Chapter 21

\title{
Pluripotent Stem Cells for Cardiac Cell Therapy: The Application of Cell Sheet Technology
}

\author{
Hidetoshi Masumoto and Jun K. Yamashita \\ Additional information is available at the end of the chapter \\ http://dx.doi.org/10.5772/56326
}

\section{Introduction}

Cardiovascular disease remains the leading cause of death worldwide despite many years of declining mortality rates in the Western world [1,2]. Myocardial infarction carries a short term mortality rate of about $7 \%$ even with aggressive therapy, and congestive heart failure with even more distressing 20\% one-year mortality [3]. Despite significant advances in therapeutic modalities and risk-reduction strategies, the substantial burden remains. This continued health problem has prompted research into new therapeutic strategies including cardiac regenerative therapy as a new approach for severe cardiac diseases resistant to conventional therapies $[4,5]$.

Acute ischemic injury and chronic cardiomyopathies lead to permanent loss of cardiac tissue, leading to heart failure. For pathologic situations, cell transplantation is thought to be an ideal therapeutic method for supplying de novo myocardium [6]. Of the available cell sources for cardiac cell therapy, stem cells (e.g. pluripotent stem cells, bone-marrow derived stem cells, skeletal myoblasts and cardiac stem cells) are now being prioritized for basic research and clinical trials [4,7]. The discoveries of various stem cell populations possessing cardiogenic potential and the advance of methods to isolate and expand these cells have shaped the notion of cell-based restorative therapy [8-11]. Despite much knowledge gained through numerous basic researches, significant challenges for true cardiac regeneration remain, and the field lacks sufficient results conclusive to support full-scale implementation of such treatments. Furthermore, results of clinical researches in cardiac stem cell therapy with a relatively small cohort scale were marginal, thus only showing little clinical advantages so far [12].

Among the stem cell types, pluripotent stem cells (PSCs) [Embryonic stem cells (ESCs) / induced pluripotent stem cells (iPSCs)] possess great capacity for cardiac regeneration mainly due to the prominent potential to expand and differentiate into most somatic cell lineages $[13,14]$. To date, no human trials using PSCs for cardiac repair have been attempted. Intensive 
translational researches, including the demonstration of effectiveness and safety, are needed to realize clinical application of PSCs.

Another concern is the actual phenomena which are taking place in the niche of transplanted site: does cardiac stem cell therapy bring de novo functional myocardium, or some indirect mechanisms mediate cardiac repair? It is reported that very few of the transplanted tissue stem cells seem to differentiate into mature cardiovascular cell types, suggesting that transplanted cells exert indirect paracrine effects by which humoral factors induce or support favorable processes, including angiogenesis, prevention of apoptosis, and promotion of healing, in the injured myocardium rather than differentiating into de novo myocardium $[4,15]$. PSCs might possess advantages in this context; defined cell populations differentiated from PSCs might be effective to elucidate underlying paracrine mechanisms in cardiac restoration compared to bulk cell mixture derived from somatic stem cells with various cell lineages and differentiation stages [16].

Concerning stem cell transplantation, as well as the transplanted cell type, the method for transplantation is also important to overcome the poor efficiency of engraftment with needle injection. A promising approach is the creation of cell sheets that better support effective engraftment of the transplants. We have shown the effectiveness of temperature-responsive cell sheet technology in basic studies [16].

In this chapter, we introduce the clarification for the progress and drawbacks of current cardiac stem cell therapy, and finally indicate the future directions of cardiac cell therapy through our recent researches combining PSCs and cell sheet technology.

\section{Various somatic stem cell populations for cardiac stem cell therapy}

To date, various somatic stem cells have been investigated for their feasibility to cardiac regenerative therapy with many basic studies.

Bone marrow hematopoietic stem cells (or circulating peripheral-blood progenitor cells) are an abundant and well characterized source of progenitor cells. A number of studies have shown that direct transplantation of bone marrow-derived cells or mobilization from endogenous reservoirs of the cell population significantly improves cardiac function $[17,18]$. However, other investigations found limited differentiation of bone marrow cells into cardiovascular cell types [19]. This suggests that beneficial results were mainly due to indirect paracrine effects such as neovascularization, independent of direct tissue regeneration.

Mesenchymal stem cells (MSCs) are a subset of stem cells found in the stroma of the bone marrow, adipose tissue, fetal membrane and many other tissues that can differentiate into osteoblasts, chondrocytes, and adipocytes [20,21] and also into small numbers of cardiomyocytes [8]. MSCs are thought to be either less immunogenic than other stem cell populations or inherently immunomodulatory [22], alleviating the need for immunosuppression prior to transplantation. Transplantation of MSCs into infarct animal models demonstrated improved left ventricular function, reduced infarct size, and increased survival rate $[8,22,23]$. The major 
disadvantage of MSCs for this clinical application is the broad differentiation capacity; MSC populations remain highly heterogeneous and are less predictable after transplantation. Some studies have shown that MSCs differentiated into osteoblasts inside ventricular tissue after transplantation [24].

Endothelial progenitor cells (EPCs) are another promising stem cell subset which accumulate to vascular injury sites from bone marrow and incorporate into the microvasculature (vasculogenesis) [9]. EPCs can be identified by the ability to acquire the expression of endothelial cell surface makers, such as cluster of differentiation molecule 133 (CD133), CD34 and so on, both in vitro and in vivo [25]. The research into their therapeutic use began with attempts to enhance their mobilization or incorporate EPCs directly into the vasculature of injured sites [26]. Preclinical studies of the injection of EPCs to infarct myocardium improved left ventricular function [15]. Although EPCs remain promising as a potential therapeutic material, they have several disadvantages for cell therapy: 1) Their heterogeneity. EPCs circulating in the peripheral blood span the full range of differentiation from angioblasts to mature endothelial cells. 2) Limited stem cell pool. Ex vivo expansion would be the only way to obtain a sufficient amount of EPCs for the treatment of an ischemic injury [27]. 3) The pool of EPCs is reduced in patients with common comorbidities of cardiac ischemia (e.g. diabetes mellitus, hypertension, and hyperlipidemia) [28].

Skeletal myoblasts (SMs) are a stem cell population derived from the satellite cells which exists beneath the basal membrane of adult skeletal muscle tissue [29]. SMs have been considered as an attractive source for cardiac restoration because of the small potential for teratoma formation, availability for autologous transplantation, resistance to ischemic condition and so on [10]. Most transplantations in animal disease models improved left ventricular function and decreased ventricular remodeling $[10,30]$. There are however, two main limitations; the first is the arrhythmogenic potential of the engrafted SMs. It is reported that only a fraction of skeletal myoblasts differentiate into cardiomyocytes after transplantation, and the generated myotubules may not synchronically work with the native myocardium [31]. A large scale clinical trial, Myoblast Autologous Grafting in Ischemic Cardiomyopathy (MAGIC) trial, showed a higher number of arrhythmic events in myoblast-treated patients [32]. The second limitation is the relatively poor engraftment of the transplanted cells into the host myocardium. It is reported that less than $10 \%$ of transplanted cells could survive within the first few days after injection in mice [33].

Several populations of cardiac progenitor / stem cells derived from mature cardiac tissue have been reported, which may hold the natural and endogenous cardiac regenerative mechanisms. Traditionally, the heart has been considered to be a post-mitotic organ, and withdrawn from the proliferative cell cycle. However, some contradictory data have reported, as cardiomyocyte proliferation and cell cycling have been observed under pathological conditions (e.g. hypertension or myocardial infarction) [34, 35] and even in the healthy heart [36]. These evidences prompted further research for such resident cardiac cells. The first cell population with stem cell properties is called the side population (SP) cells. Isolated cardiac SP cells represent cardiac and vascular progenitor cells and can differentiate into cardiomyocytes, endothelial cells, or smooth muscle cells [37]. The second progenitor population is the cells expressing the stem 
cell factor receptor c-Kit (also designed as CD117), which are located in small clusters within the adult cardiac tissue. $\mathrm{c}-\mathrm{Kit}^{+}$cells hold regenerative potential after transplantation and give rise to cardiomyocytes, endothelial cells, and smooth muscle cells [38]. The third cell type expresses stem cell antigen 1 (Sca-1). Sca- $1^{+}$cells migrate to infarcted myocardium and differentiate into cardiomyocytes around the injured area [39]. Finally, enzymatic digestion of heart tissue obtained via endomyocardial biopsy or during cardiac surgery yields cardiac progenitor cells that form what is called cardiospheres. Cardiosphere derived cells (CDCs) can also differentiate into cardiomyocytes, endothelial cells, and smooth muscle cells, exhibiting prominent capacities for proliferation and differentiation [11]. This population can be differentiated into aggregates of cardiomyocytes that when transplanted into injured myocardium produced functional improvement in preclinical studies [40]. It is unclear whether the various cardiac stem cells shown here are different populations, or represent various stages of a single cell lineage. A major limitation of cardiac progenitor / stem cell populations is that the cardiac stem cell pool appears to diminish along with age, which may limit the efficacy of regeneration in elderly people [41]. Considering that it is mostly the elderly who suffer increased mortality from cardiac ischemia, intensive research aiming to rejuvenate this senescent stem cell population is required.

Many clinical studies have been conducted using these somatic stem cells so far: TOPCAREAMI [42], BOOST [43], REPAIR-AMI [44], LateTime [45] (Bone marrow hematopoietic stem cells), REGENT [46] (EPCs), MAGIC [32], CAuSMIC [47] (SMs), CADUCEUS [48], SCIPIO [49] (cardiac progenitor / stem cells) and so on. However, most of these clinical studies have shown relatively limited clinical benefits in general. These marginal results indicate that more efficient approaches for stem cell therapy are needed to realize full-scale stem cell-based therapy.

\section{Advantages of pluripotent stem cells in cardiac regeneration}

Embryonic stem cells (ESCs) are one of the stem cell populations which can be removed from the inner cell mass of the blastocyst and expanded in vitro with practically no limitations [13]. Yamanaka and colleagues have discovered that reprogramming of adult somatic cells with transcription factor genes that confer pluripotency generates ESC-like cells, called induced pluripotent stem cells (iPSCs) [14,50]. Among the stem cell types, these pluripotent stem cells (PSCs) [ESCs / iPSCs] possess great capacity especially for cardiac regeneration due to several reasons.

The first reason is that PSCs can be expanded practically indefinitely in vitro remaining pluripotent in an undifferentiated state in culture, and can give rise to most somatic cell lineages once allowed to differentiate. In this regard, the regenerative capacity is theoretically limitless [51]. The merit of PSCs is larger especially for the heart compared to other organs, such as endocrine or sensory organs, as the heart functions as an assembly of a large number of cells including cardiomyocytes and other cell types (e.g. vascular cells, cardiac fibroblasts), and numerous $\left(>10^{8}\right)$ heart-composing cells might be required to fully compensate for the damaged human heart [5]. 
The second reason is that the capacity for the differentiation towards a desired cell type, such as cardiomyocytes or other vascular cell types is the highest among various stem cell populations known to possess cardiogenic potential. The differentiation of PSCs can be driven towards cardiomyocytes or others by culture conditions as monolayers or embryoid bodies in various growth media [52-55]. Previously, we have developed a novel monolayer culturebased ESC / iPSC differentiation system that recapitulates early cardiovascular developmental processes using Flk1 (also designed as vascular endothelial cell growth factor [VEGF] receptor-2)-positive cells as common cardiovascular progenitors. Cardiovascular cell types, namely cardiomyocytes [53], endothelial cells, and vascular mural cells [52], can be systematically induced and purified with this system (Figure 1A). In fact, of the various stem cell populations studied so far, PSCs have demonstrated probably the greatest capacity for cardiac cell differentiation and long-term cell survival [56].

The third reason is that PSCs might be advantageous for further elucidation of regenerative mechanisms. In the field of cardiac restoration with stem cell therapy, it has been widely believed that transplanted cells act as an inducer of indirect paracrine effects such as angiogenesis, prevention of apoptosis, and so on rather than regeneration of de novo myocardium $[4,15]$. Considering this point, the transplantation of somatic stem cells, which are largely performed thus far as mentioned above, may raise a question, "which cells are really effective?", because the transplanted cells from somatic stem cells might consist of heterogeneous cell populations. In this regard, the transplantation of defined cardiovascular cell populations systematically derived from PSCs might be much more superior to that of somatic stem cellderived populations for the sake of the elucidation of regenerative mechanisms (Figure 1B).

The final reason is the discovery of iPSCs. The generation of iPSCs by reprogramming autologous somatic cells with genes regulating pluripotency may resolve the ethical and immunogenic issues associated with the use of ESCs. Furthermore, we have reported that cardiovascular cell types can be differentiated respectively from mouse iPSCs almost identically with those from mouse ESCs [57]. This indicates that iPSCs possess almost the same regenerative capacity as that of ESCs. A potent differentiation protocol based on high-density monolayer culture and chemically defined factors, and modifications thereof, have been reported to induce cardiomyocytes from human iPSCs with a robust efficiency of $40-70 \%$ [54, 58]. The application of this method would strongly promote cardiac regeneration using human iPSCs.

The transplantation of cardiac cells derived from PSCs has been tested in animal studies with encouraging results $[16,54]$. However, no human studies using PSCs for cardiac repair have been attempted so far. A major concern regarding iPSC transplantation as a treatment modality is related to the potential tumor formation. The differentiating cells from PSCs contain derivatives from three germ layers (ectoderm, mesoderm and endoderm), possessing the capacity to differentiate along any or all of these three lineages. This increases the risk of teratoma formation at the transplantation site. Although such teratomas are believed to be largely benign, some teratoma cells have been reported to express markers similar to those seen in malignant tumors [59]. Recently, protocols for generating human iPSCs without genomic integration by utilizing episomal vectors [60] or human artificial chromosome vectors 
A

Mouse

Undifferentiated

ES / iPS cells
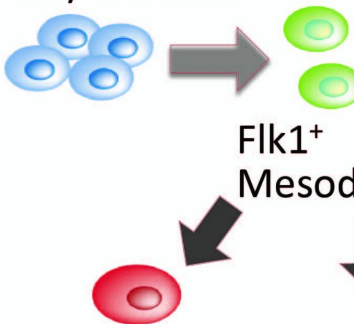

Flk1 $^{+}$

Mesoderm cells

Blood cells
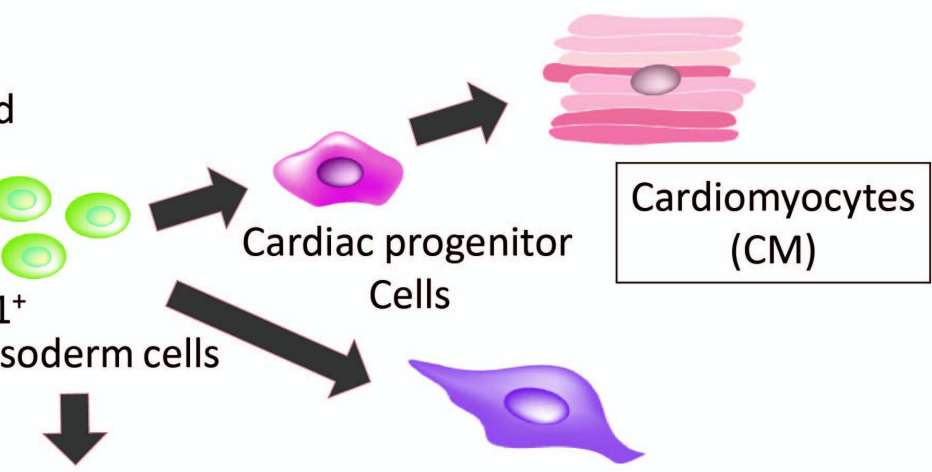

Cells

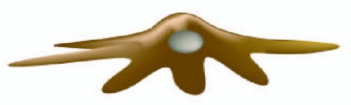

Endothelial cells (EC)

\section{Vascular mural cells (MC)}

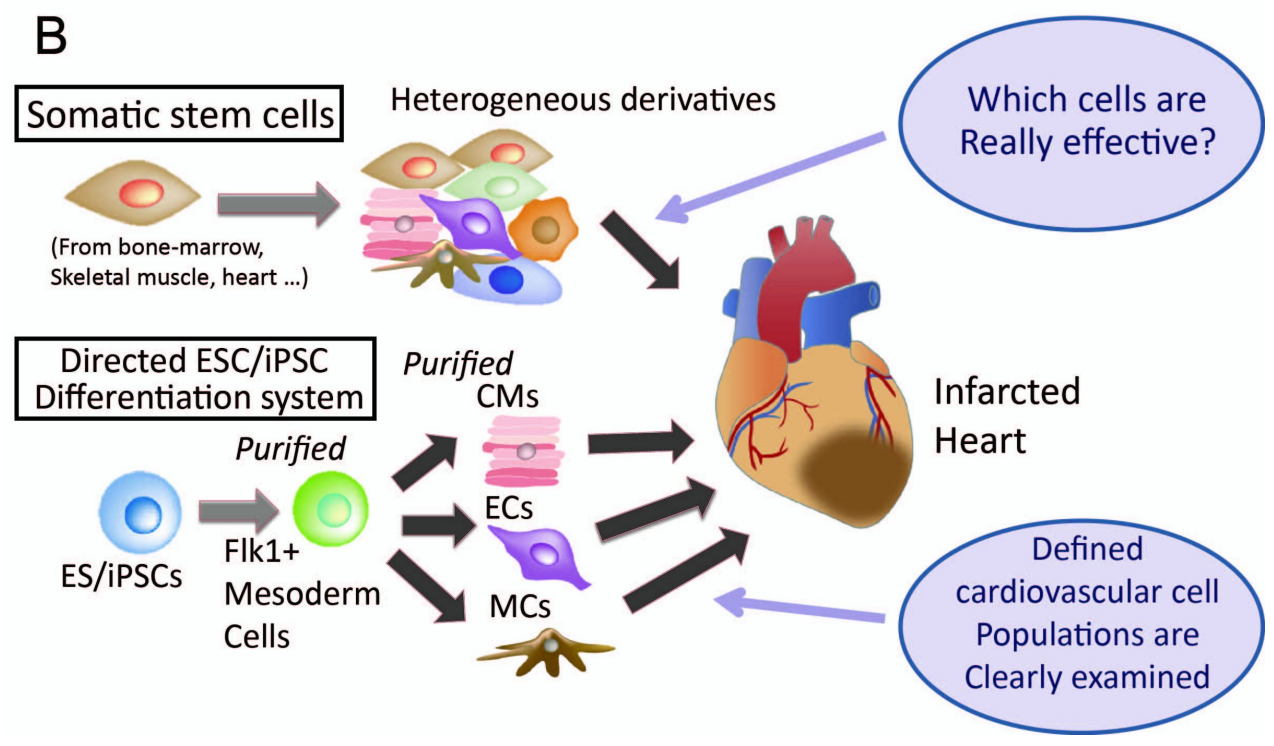

Figure 1. The advantages of PSCS for cardiac regeneration. (A): The capacity for the differentiation towards a desired cardiac cell type. The scheme of directed mouse PSC differentiation system from Flk $1^{+}$mesoderm cells as a common progenitor is shown. (B): Effectiveness for further elucidation of regenerative mechanisms. The usage of somatic stem cells (upper) may lead to the transplantation of heterogeneous derivatives in lineage and differentiation stage. On the other hand, the usage of directed PSC differentiation system with purifying processes (lower) clarify which cell populations are actually transplanted. ES cell, embryonic stem cell; iPS cell, induced pluripotent stem cell. 
[61] have been reported. These may reduce tumorigenesis due to mutations, which could otherwise limit the clinical application of iPSCs.

Considering the results of these basic studies, PSCs (especially iPSCs) are currently recognized to be one of the most promising cell sources for cardiac regeneration. However, further careful exploration for the feasibility of this new modality will be needed to realize the clinical application.

\section{Cell sheet technology as a novel method for PSC-derived cell transplantation}

In addition to the transplanted cell type, the transplantation method is also important to overcome poor efficiency of engraftment associated with needle injection. The low level of grafted cell survival and engraftment diminishes their potential for paracrine effects, besides regeneration of de novo myocardium, and is a major technical limitation for stem cell therapy [62]. It is reported that $>70 \%$ of injected cells die during the first 48 hours after needle injection, progressively diminishing during the following days possibly due to the hypoxic, inflammatory, and/or fibrotic environment [63]. Another report shows that only 5.4 to $8.8 \%$ of microspheres remain just after direct injection into the beating myocardium due to massive mechanical loss [64]. To overcome this problem, a combination of bioengineering techniques have been developed and investigated for their efficacy, suggesting that these new strategies may improve the efficiency of stem cell therapies [65].

Initial experiments were performed by combining the cells with injectable biomaterials such as collagen, fibrin, gelatin or matrigel as a sccafold. In general, early results showed an increased survival of the transplanted cells, and a greater improvement in cardiac function of the treated hearts [66]. However, these approaches did not assure complete cell retention or an adequate distribution of the transplanted cells within the host heart.

The creation of cell sheets without scaffold support would be a more promising approach. The advantages of this method are as follows: 1) Potent increase of the efficiency of transplantation compared to that of needle injection. 2) Potential for construction of three-dimentional tissuelike structure as a graft. 3) Avoidance of inflammatory reactions against the biomaterials constituting the scaffolds. 4) Larger scalability and accessibility due to two-dimensional cell culture.

Several methods have been reported for cell sheet formation [67-69]. Among them, we have utilized temperature-responsive culture surface-based method [16]. This technique was made possible by using a culture dish covalently grafted with temperature-responsive polymer poly (N-isopropylacrylamide) (PIPAAm) which enables the generation of cell sheets without enzymatic digestion, retaining intact extracellular matrices or adhesion molecules [67]. The benefits of this technique have been demonstrated by many experiments of stem cell therapy such as the transplantation of monolayer adipose tissue-derived MSCs to the infarcted rat heart 
A

B
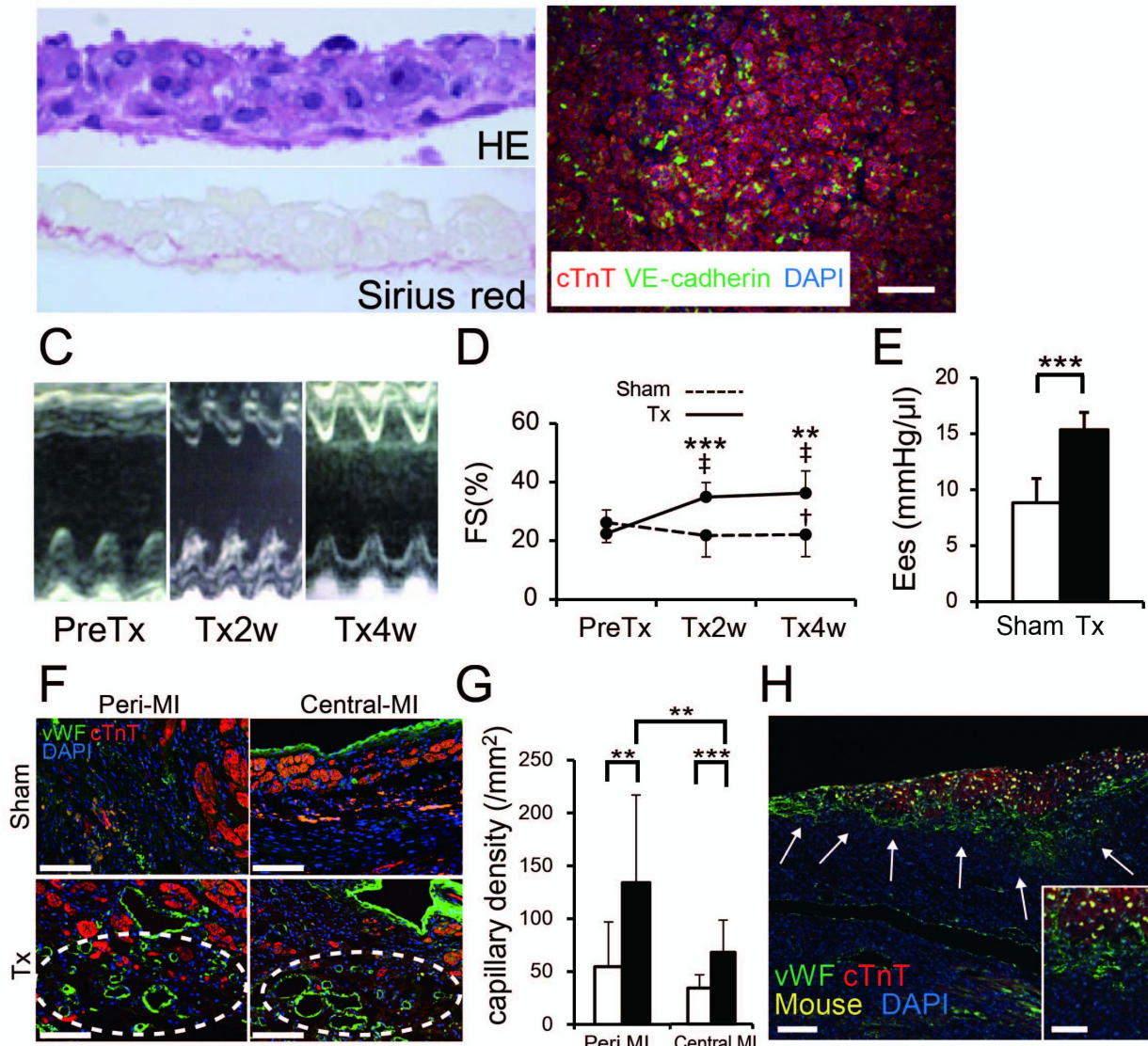

G

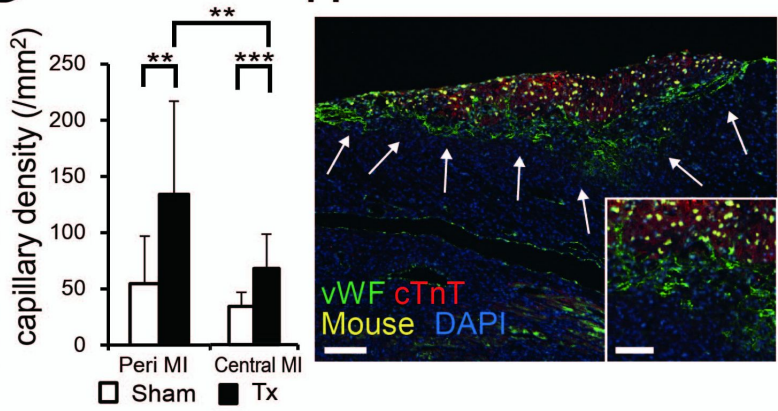

Figure 2. The improvement of infarcted heart function after transplantation of cardiac tissue sheets bioengineered with mouse ES cell-derived defined cardiac cell populations. (A): Cross-sections of the sheet. Upper panel: H\&E staining showing cell appearance of the sheet. Lower panel: Sirius red staining showing intact extracellular matrix. (B): Immunostaining of sheets for $\mathrm{CTnT}$ (red), VE-cadherin (green), and DAPI. (C,D): Echocardiogram ( $n=9)$. (C): Representative M-mode image. Note that infarct anterior wall started to move 2-4 weeks after transplantation (Tx). (D): Fractional shortening (FS). (E): LV pressure-volume loop study 4 weeks after $T x(n=8)$. Ees: End-systolic elastance. $(F, G)$ : Capillary formation at Tx-d28. (F): Double staining for VWF (ECs, green) and cTnT (cardiomyocytes [CMs], red) at peri-MI and central-MI areas. Note that newly formed capillaries are clearly observed in transplantation group (dotted circles). (G): Quantification of capillary density (capillary number per square millimeter). Peri-MI area (left panel) and central-MI area (right panel) (15 views each). (H): Triple staining for VWF, cTnT, and species-specific fluorescent in situ hybridization (mouse nuclei, yellow) ( $T x-d 3)$. Most of the accumulated vWF-positive cells are negative for mouse nuclear staining (arrows). Inset: higher magnification view. ${ }^{* *}, p<.01$; and ${ }^{* * *}, p<.001$ (unpaired t test),,$+ p<.05$ and $\neq, p<.01$ (vs. PreTx, paired t test). PreTx; Pretransplantation, Tx2w, Tx4w; 2 and 4 weeks after transplantation, respectively. Scale bars: $200 \mu \mathrm{m}$ in (B), $100 \mu \mathrm{m}$ in (F) and (H) (main panel), $50 \mu \mathrm{m}$ in (H) (inset). HE, Hematoxylin and Eosin; $\mathrm{CTnT}$, cardiac troponin-T; DAPI, 4,6-diamidino-2-phenylindole; vWF, von Willebrandfactor.; MI, myocardial infarction. (quote from ref. 16 with revision) 
A
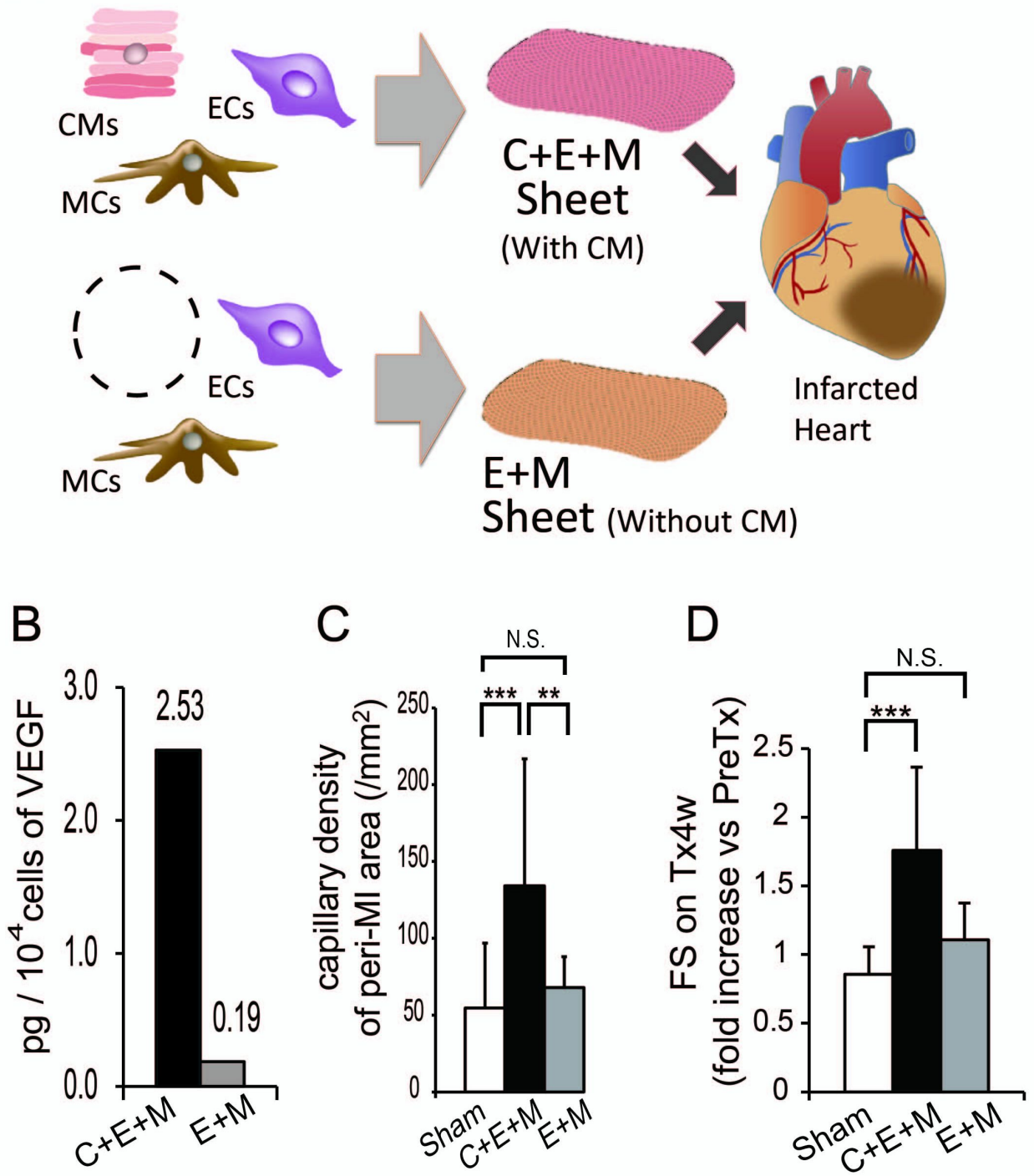

Figure 3. Cell type-controlled sheet analyses. $(A)$ : The Scheme of cell sheets with $C M s(C+E+M)$ or without $C M s$ $(E+M)$. (B): ELISA for VEGF secretion (picogram per10 cells) in culture supernatants of $C+E+M$ and $E+M$ sheets. $(C, D)$ : Transplantation of sham operation $(n=9)$ versus $C+E+M$ sheets $(n=9)$ versus $E+M$ sheets $(n=3)(T x-d 28)$. (C): Capillary density in peri-MI area (capillary number per square millimeter). (15 views each). (D): Fractional shortening (FS) on echocardiogram (fold increase vs. PreTx). **, $p<.01$, and ***, $p<.001$ (unpaired t test). C: cardiomyocytes, E: endothelial cells, M: vascular mural cells. N.S., not significant; VEGF, vascular endothelial cell growth factor. (quote from ref. 16 with revision). 
[23]. Recently, we have reported transplantation of a three-layered cardiac tissue sheet bioengineered with mouse ESC-derived defined cardiac cell populations in the infarcted heart (Figure 2) [16]. In both cases, increased tissue neovascularization together with a prominent attenuation of cardiac remodeling responsible for the improvement in cardiac function were demonstrated. Furthermore, our research indicated the potential for cell sheet-based prospective elucidation of the cellular mechanisms of cardiac restoration. The combinations of cell populations composing the transplanted cell sheets enabled us to elucidate the contributions of each cell type (for example, the comparison of cell sheets with or without cardiomyocytes is useful for the elucidation of the cellular function of cardiomyocytes). This cell-type controlled analysis led us to identify one of the important cellular mechanisms of cardiac restoration following cell therapy, that is, cardiomyocytes are essential for the functional improvement of ischemic heart through neovascularization (Figure 3). These results show that the tissue-like cell sheet system is advantageous for the elucidation of cardiac regenerative mechanism, as well as for therapeutic purposes.

\section{Future directions}

One future direction of this PSC-derived cell sheet technology is its utilization as a novel experimental tool for elucidation of regenerative mechanisms. Although the present results of clinical trials using stem cell therapy are marginal, further elucidation of the actual mechanisms of cardiac repair following cell therapy would enhance the potential of stem cell therapy to be a full-scale therapy. It would be a breakthrough for further improvement of cardiac cell therapy to understand the role of each cell population as well as the various cellular interactions in the chaos of heterogeneity.

Another direction is a more efficient survival of transplanted sheets to realize regeneration of functioning de novo myocardium. Considering that more cells that survived were observed in peri-infarction than central infarction region in our study [16], it would be possible that the severe ischemic condition may not be suitable for sheet survival. Novel techniques increasing blood supply in the graft should be applied, such as prevascularization in 3-dimensional tissue formation $[70,71]$ or vascularized flap grafts.

\section{Conclusion}

In this chapter, we have reviewed the status quo of current cardiac stem cell therapy, and shown the promising potential of PSC-derived cardiac tissue-like sheets. The knowledge yielded from this cell sheet-based study would provide a hallmark for cell therapy with PSCs and a strategic principle for future cardiac restoration therapy. 


\section{Author details}

Hidetoshi Masumoto $^{1,2^{*}}$ and Jun K. Yamashita ${ }^{1}$

*Address all correspondence to: masumoto@kuhp.kyoto-u.ac.jp

1 Laboratory of Stem Cell Differentiation, Department of Cell Growth and Differentiation, Center for iPS Cell Research and Application (CiRA), Kyoto University, Kyoto, Japan

2 Department of Cardiovascular Surgery, Kyoto University Graduate School of Medicine, Kyoto, Japan

\section{References}

[1] World Health Organization (WHO)The global burden of disease: 2004 update. 2008. http://www.who.int/healthinfo/global_burden_disease/2004_report_update/en/ index.html accessed 31 August (2012).

[2] Ford, E. S, \& Capewell, S. (2011). Proportion of the Decline in Cardiovascular Mortality Disease due to Prevention Versus Treatment: Public Health Versus Clinical Care. Annu Rev Public Health , 32, 5-22.

[3] Assessment of the Safety and Efficacy of a New Thrombolytic Regimen (ASSENT)-3 Investigators(2001). Efficacy and safety of tenecteplase in combination with enoxaparin, abciximab, or unfractionated heparin: the ASSENT-3 randomised trial in acute myocardial infarction. Lancet, 358, 605-613.

[4] Joggerst, S. J, \& Hatzopoulos, A. K. (2009). Stem cell therapy for cardiac repair: benefits and barriers. Expert Rev Mol Med 11,e20.

[5] Masumoto, H, \& Sakata, R. Cardiovascular surgery for realization of regenerative medicine. Gen Thorac Cardiovasc Surg. In press.

[6] Sakakibara, Y, Tambara, K, Lu, F, Nishina, T, Sakaguchi, G, Nagaya, N, Nishimura, K, Li, R. K, Weisel, R. D, \& Komeda, M. (2002). Combined procedure of surgical repair and cell transplantation for left ventricular aneurysm: an experimental study. Circulation 106,II197., 193.

[7] Chien, K. R. (2008). Regenerative medicine and human models of human disease. Nature , 453, 302-305.

[8] Tomita, S, Li, R. K, Weisel, R. D, Mickle, D. A, Kim, E. J, Sakai, T, \& Jia, Z. Q. (1999). Autologous transplantation of bone marrow cells improves damaged heart function. Circulation 100,IIII256., 247. 
[9] Asahara, T, Murohara, T, Sullivan, A, Silver, M, Van Der Zee, R, Li, T, Witzenbichler, B, Schatteman, G, \& Isner, J. M. (1997). Isolation of putative progenitor endothelial cells for angiogenesis. Science , 275, 964-967.

[10] Murry, C. E, Wiseman, R. W, Schwartz, S. M, \& Hauschka, S. D. (1996). Skeletal myoblast transplantation for repair of myocardial necrosis. J Clin Invest , 98, 2512-2523.

[11] Messina, E, De Angelis, L, Frati, G, Morrone, S, Chimenti, S, Fiordaliso, F, Salio, M, Battaglia, M, Latronico, M. V, Coletta, M, et al. (2004). Isolation and expansion of adult cardiac stem cells from human and murine heart. Circ Res , 95, 911-921.

[12] Rosenzweig, A. (2006). Cardiac cell therapy--mixed results from mixed cells. N Engl J Med , 355, 1274-1277.

[13] Thomson, J. A, Itskovitz-eldor, J, Shapiro, S. S, Waknitz, M. A, Swiergiel, J. J, Marshall, V. S, \& Jones, J. M. (1998). Embryonic stem cell lines derived from human blastocysts. Science , 282, 1145-1147.

[14] Takahashi, K, Tanabe, K, Ohnuki, M, Narita, M, Ichisaka, T, Tomoda, K, \& Yamanaka, S. (2007). Induction of pluripotent stem cells from adult human fibroblasts by defined factors. Cell , 131, 861-872.

[15] Kocher, A. A, Schuster, M. D, Szabolcs, M. J, Takuma, S, Burkhoff, D, Wang, J, Homma, S, Edwards, N. M, \& Itescu, S. (2001). Neovascularization of ischemic myocardium by human bone-marrow derived angioblasts prevents cardiomyocyte apoptosis, reduces remodeling and improves cardiac function. Nat Med , 7, 430-436.

[16] Masumoto, H, Matsuo, T, Yamamizu, K, Uosaki, H, Narazaki, G, Katayama, S, Marui, A, Shimizu, T, Ikeda, T, Okano, T, et al. (2012). Pluripotent stem cell-engineered cell sheets reassembled with defined cardiovascular populations ameliorate reduction in infarct heart function through cardiomyocyte-mediated neovascularization. Stem Cells , 30, 1196-1205.

[17] Orlic, D, Kajstura, J, Chimenti, S, Jakoniuk, I, Anderson, S. M, Li, B, Pickel, J, Mckay, R, Nadal-ginard, B, Bodine, D. M, et al. (2001). Bone marrow cells regenerate infarcted myocardium. Nature , 410, 701-705.

[18] Orlic, D, Kajstura, J, Chimenti, S, Limana, F, Jakoniuk, I, Quaini, F, Nadal-ginard, B, Bodine, D. M, Leri, A, \& Anversa, P. (2001). Mobilized bone marrow cells repair the infarcted heart, improving function and survival. Proc Natl Acad Sci USA. , 98, 10344-10349.

[19] Murry, C. E, Soonpaa, M. H, Reinecke, H, Nakajima, H, Nakajima, H. O, Rubart, M, Pasumarthi, K. B, Virag, J. I, Bartelmez, S. H, Poppa, V, et al. (2004). Haematopoietic stem cells do not transdifferentiate into cardiac myocytes in myocardial infarcts. Nature , 428, 664-668. 
[20] Jiang, Y, Jahagirdar, B. N, Reinhardt, R. L, Schwartz, R. E, Keene, C. D, Ortiz-gonzalez, X. R, Reyes, M, Lenvik, T, Lund, T, Blackstad, M, et al. (2002). Pluripotency of mesenchymal stem cells derived from adult marrow. Nature , 418, 41-49.

[21] Ishikane, S, Yamahara, K, Sada, M, Harada, K, Kodama, M, Ishibashi-ueda, H, Hayakawa, K, Mishima, K, Iwasaki, K, Fujiwara, M, et al. (2010). Allogeneic administration of fetal membrane-derived mesenchymal stem cells attenuates acute myocarditis in rats. J Mol Cell Cardiol. , 49, 753-761.

[22] Dai, W, Hale, S. L, Martin, B. J, Kuang, J. Q, Dow, J. S, Wold, L. E, \& Kloner, R. A. (2005). Allogeneic mesenchymal stem cell transplantation in postinfarcted rat myocardium: short- and long-term effects. Circulation , 112, 214-223.

[23] Miyahara, Y, Nagaya, N, Kataoka, M, Yanagawa, B, Tanaka, K, Hao, H, Ishino, K, Ishida, H, Shimizu, T, Kangawa, K, et al. (2006). Monolayered mesenchymal stem cells repair scarred myocardium after myocardial infarction. Nat Med , 12, 459-465.

[24] Yoon, Y. S, Park, J. S, Tkebuchava, T, Luedeman, C, \& Losordo, D. W. (2004). Unexpected severe calcification after transplantation of bone marrow cells in acute myocardial infarction. Circulation , 109, 3154-3157.

[25] Hristov, M, \& Weber, C. (2008). Endothelial progenitor cells in vascular repair and remodeling. Pharmacol Res , 58, 148-151.

[26] Llevadot, J, Murasawa, S, Kureishi, Y, Uchida, S, Masuda, H, Kawamoto, A, Walsh, K, Isner, J. M, \& Asahara, T. (2001). HMG-CoA reductase inhibitor mobilizes bone marrow-derived endothelial progenitor cells. J Clin Invest, 108, 399-405.

[27] Jujo, K, Ii, M, \& Losordo, D. W. (2008). Endothelial progenitor cells in neovascularization of infarcted myocardium. J Mol Cell Cardiol , 45, 530-544.

[28] Vasa, M, Fichtlscherer, S, Aicher, A, Adler, K, Urbich, C, Martin, H, Zeiher, A. M, \& Dimmeler, S. (2001). Number and migratory activity of circulating endothelial progenitor cells inversely correlate with risk factors for coronary artery disease. Circ Res 89,EE7., 1.

[29] Buckingham, M, \& Montarras, D. Skeletal muscle stem cells. ((2008). Curr Opin Genet Dev. , 18, 330-336.

[30] Taylor, D. A, Atkins, B. Z, Hungspreugs, P, Jones, T. R, Reedy, M. C, Hutcheson, K. A, Glower, D. D, \& Kraus, W. E. (1998). Regenerating functional myocardium: improved performance after skeletal myoblast transplantation. Nat Med , 4, 929-933.

[31] Farahmand, P, Lai, T. Y, Weisel, R. D, Fazel, S, Yau, T, Menasche, P, \& Li, R. K. (2008). Skeletal myoblasts preserve remote matrix architecture and global function when implanted early or late after coronary ligation into infarcted or remote myocardium. Circulation 118,SS137., 130.

[32] Menasche, P, Alfieri, O, Janssens, S, Mckenna, W, Reichenspurner, H, Trinquart, L, Vilquin, J. T, Marolleau, J. P, Seymour, B, Larghero, J, et al. (2008). The Myoblast Au- 
tologous Grafting in Ischemic Cardiomyopathy (MAGIC) trial: first randomized placebo-controlled study of myoblast transplantation. Circulation , 117, 1189-1200.

[33] Suzuki, K, Murtuza, B, Beauchamp, J. R, Smolenski, R. T, Varela-carver, A, Fukushima, S, Coppen, S. R, Partridge, T. A, \& Yacoub, M. H. (2004). Dynamics and mediators of acute graft attrition after myoblast transplantation to the heart. FASEB J , 18, 1153-1155.

[34] Anversa, P, Palackal, T, Sonnenblick, E. H, Olivetti, G, \& Capasso, J. M. (1990). Hypertensive cardiomyopathy. Myocyte nuclei hyperplasia in the mammalian rat heart. J Clin Invest, 85, 994-997.

[35] Beltrami, A. P, Urbanek, K, Kajstura, J, Yan, S. M, Finato, N, Bussani, R, Nadal-ginard, B, Silvestri, F, Leri, A, Beltrami, C. A, et al. (2001). Evidence that human cardiac myocytes divide after myocardial infarction. N Engl J Med , 344, 1750-1757.

[36] Bergmann, O, Bhardwaj, R. D, Bernard, S, \& Zdunek, S. Barnabe'-Heider F, Walsh S, Zupicich J, Alkass K, Buchholz BA, Druid H et al. ((2009). Evidence for cardiomyocyte renewal in humans. Science, 324, 98-102.

[37] Oyama, T, Nagai, T, Wada, H, Naito, A. T, Matsuura, K, Iwanaga, K, Takahashi, T, Goto, M, Mikami, Y, Yasuda, N, et al. (2007). Cardiac side population cells have a potential to migrate and differentiate into cardiomyocytes in vitro and in vivo. J Cell Biol , 176, 329-341.

[38] Beltrami, A. P, Barlucchi, L, Torella, D, Baker, M, Limana, F, Chimenti, S, Kasahara, H, Rota, M, Musso, E, Urbanek, K, et al. (2003). Adult cardiac stem cells are multipotent and support myocardial regeneration. Cell , 114, 763-776.

[39] Oh, H, Bradfute, S. B, Gallardo, T. D, Nakamura, T, Gaussin, V, Mishina, Y, Pocius, J, Michael, L. H, Behringer, R. R, Garry, D. J, et al. (2003). Cardiac progenitor cells from adult myocardium: homing, differentiation, and fusion after infarction. Proc Natl Acad Sci USA , 100, 12313-12318.

[40] Takehara, N, Tsutsumi, Y, Tateishi, K, Ogata, T, Tanaka, H, Ueyama, T, Takahashi, T, Takamatsu, T, Fukushima, M, Komeda, M, et al. (2008). Controlled delivery of basic fibroblast growth factor promotes human cardiosphere-derived cell engraftment to enhance cardiac repair for chronic myocardial infarction. J Am Coll Cardiol , 52, 1858-65.

[41] Torella, D, \& Ellison, G. M. Me'ndez-Ferrer S, Ibanez B and Nadal-Ginard B. ((2006). Resident human cardiac stem cells: role in cardiac cellular homeostasis and potential for myocardial regeneration. Nat Clin Pract Cardiovasc Med 3,SS13., 8.

[42] Leistner, D. M, Fischer-rasokat, U, Honold, J, \& Seeger, F. H. Scha ${ }^{\circ}$ chinger V, Lehmann R, Martin H, Burck I, Urbich C, Dimmeler S et al. ((2011). Transplantation of progenitor cells and regeneration enhancement in acute myocardial infarction (TOP- 
CARE-AMI): final 5-year results suggest longterm safety and efficacy. Clin Res Cardiol , 100, 925-934.

[43] Meyer, G. P, Wollert, K. C, Lotz, J, Steffens, J, Lippolt, P, Fichtner, S, Hecker, H, Schaefer, A, Arseniev, L, Hertenstein, B, et al. (2006). Intracoronary bone marrow cell transfer after myocardial infarction: eighteen months' follow-up data from the randomized, controlled BOOST (BOne marrOw transfer to enhance ST-elevation infarct regeneration) trial. Circulation , 113, 1287-1294.

[44] Assmus, B, Rolf, A, \& Erbs, S. Elsa ${ }^{\circ}$ sser A, Haberbosch W, Hambrecht R, Tillmanns H, Yu J, Corti R, Mathey DG et al. ((2010). Clinical outcome 2 years after intracoronary administration of bone marrow-derived progenitor cells in acute myocardial infarction. Circ Heart Fail , 3, 89-96.

[45] Traverse, J. H, Henry, T. D, Ellis, S. G, Pepine, C. J, Willerson, J. T, Zhao, D. X, Forder, J. R, Byrne, B. J, Hatzopoulos, A. K, Penn, M. S, et al. (2011). Effect of intracoronary delivery of autologous bone marrow mononuclear cells 2 to 3 weeks following acute myocardial infarction on left ventricular function: the LateTIME randomized trial. JAMA , 306, 2110-2119.

[46] Tendera, M, Wojakowski, W, Ruzyllo, W, Chojnowska, L, Kepka, C, Tracz, W, Musialek, P, Piwowarska, W, Nessler, J, Buszman, P, et al. (2009). Intracoronary infusion of bone marrowderived selected CD34+CXCR4+ cells and non-selected mononuclear cells in patients with acute STEMI and reduced left ventricular ejection fraction: results of randomized, multicenter Myocardial Regeneration by Intracoronary Infusion of Selected Population of Stem Cells in Acute Myocardial Infarction (REGENT) Trial. Eur Heart J , 30, 1313-1321.

[47] Dib, N, Dinsmore, J, Lababidi, Z, White, B, Moravec, S, Campbell, A, Rosenbaum, A, Seyedmadani, K, Jaber, W. A, Rizenhour, C. S, et al. (2009). One-year follow-up of feasibility and safety of the first US, randomized, controlled study using 3-dimensional guided catheter-based delivery of autologous skeletal myoblasts for ischemic cardiomyopathy (CAuSMIC study). JACC Cardiovasc Interv , 2, 9-16.

[48] Makkar, R. R, Smith, R. R, Cheng, K, Malliaras, K, Thomson, L. E, Berman, D, Czer, L. S, Marbán, L, Mendizabal, A, Johnston, P. V, et al. (2012). Intracoronary cardiosphere-derived cells for heart regeneration after myocardial infarction (CADUCEUS): a prospective, randomised phase 1 trial. Lancet , 379, 895-904.

[49] Bolli, R, Chugh, A. R, Amario, D, Loughran, D, Stoddard, J. H, Ikram, M. F, Beache, S, Wagner, G. M, Leri, S. G, \& Hosoda, A. T et al. ((2011). Cardiac stem cells in patients with ischaemic cardiomyopathy (SCIPIO): initial results of a randomised phase 1 trial. Lancet, 378, 1847-1857.

[50] Takahashi, K, \& Yamanaka, S. (2006). Induction of pluripotent stem cells from mouse embryonic and adult fibroblast cultures by defined factors. Cell , 126, 663-676. 
[51] Murry, C. E, \& Keller, G. (2008). Differentiation of embryonic stem cells to clinically relevant populations: lessons from embryonic development. Cell , 132, 661-680.

[52] Yamashita, J, Itoh, H, Hirashima, M, Ogawa, M, Nishikawa, S, Yurugi, T, Naito, M, Nakao, K, \& Nishikawa, S. (2000). Flk1-positive cells derived from embryonic stem cells serve as vascular progenitors. Nature , 408, 92-96.

[53] Yamashita, J. K, Takano, M, Hiraoka-kanie, M, Shimazu, C, Yan, P, Yanagi, K, Nakano, A, Inoue, E, Kita, F, \& Nishikawa, S. (2005). Prospective identification of cardiac progenitors by a novel single cell-based cardiomyocyte induction. FASEB J , 19, 1534-1536.

[54] Laflamme, M. A, Chen, K. Y, Naumova, A. V, Muskheli, V, Fugate, J. A, Dupras, S. K, Reinecke, H, Xu, C, Hassanipour, M, Police, S, et al. (2007). Cardiomyocytes derived from human embryonic stem cells in pro-survival factors enhance function of infarcted rat hearts. Nat Biotechnol , 25, 1015-1024.

[55] Sone, M, Itoh, H, Yamahara, K, Yamashita, J. K, Yurugi-kobayashi, T, Nonoguchi, A, Suzuki, Y, Chao, T. H, Sawada, N, Fukunaga, Y, et al. (2007). Pathway for differentiation of human embryonic stem cells to vascular cell components and their potential for vascular regeneration. Arterioscler Thromb Vasc Biol , 27, 2127-2134.

[56] Van Laake, L. W, Passier, R, Monshouwer-kloots, J, Verkleij, A. J, Lips, D. J, \& Freund, C. den Ouden K, Ward-van Oostwaard D, Korving J, Tertoolen LG et al. ((2007). Human embryonic stem cell-derived cardiomyocytes survive and mature in the mouse heart and transiently improve function after myocardial infarction. Stem Cell Res. , 1, 9-24.

[57] Narazaki, G, Uosaki, H, Teranishi, M, Okita, K, Kim, B, Matsuoka, S, Yamanaka, S, \& Yamashita, J. K. (2008). Directed and systematic differentiation of cardiovascular cells from mouse induced pluripotent stem cells. Circulation , 118, 498-506.

[58] Uosaki, H, Fukushima, H, Takeuchi, A, Matsuoka, S, Nakatsuji, N, Yamanaka, S, \& Yamashita, J. K. (2011). Efficient and scalable purification of cardiomyocytes from human embryonic and induced pluripotent stem cells by VCAM1 surface expression. PLoS One 6,e23657.

[59] Blum, B, \& Benvenisty, N. (2008). The tumorigenicity of human embryonic stem cells. Adv Cancer Res , 100, 133-158.

[60] Okita, K, Matsumura, Y, Sato, Y, Okada, A, Morizane, A, Okamoto, S, Hong, H, Nakagawa, M, Tanabe, K, Tezuka, K, et al. (2011). A more efficient method to generate integration-free human iPS cells. Nat Method , 8, 409-412.

[61] Hiratsuka, M, Uno, N, Ueda, K, Kurosaki, H, Imaoka, N, Kazuki, K, Ueno, E, Akakura, Y, Katoh, M, Osaki, M, et al. (2011). Integration-free iPS cells engineered using human artificial chromosome vectors. PLoS One 6,e25961. 
[62] Pelacho, B, Mazo, M, Gavira, J. J, \& Prósper, F. (2011). Adult stem cells: from new cell sources to changes in methodology. J Cardiovasc Transl Res , 4, 154-160.

[63] Müller-ehmsen, J, Whittaker, P, Kloner, R. A, Dow, J. S, Sakoda, T, Long, T. I, Laird, P. W, \& Kedes, L. (2002). Survival and development of neonatal rat cardiomyocytes transplanted into adult myocardium. J Mol Cell Cardiol , 34, 107-116.

[64] Teng, C. J, Luo, J, Chiu, R. C, \& Shum-tim, D. (2006). Massive mechanical loss of microspheres with direct intramyocardial injection in the beating heart: implications for cellular cardiomyoplasty. J Thorac Cardiovasc Surg , 132, 628-632.

[65] Masumoto, H, \& Yamashita, J. K. Strategies in cell therapy for cardiac regeneration. Inflammation and Regeneration. In press.

[66] Cortes-morichetti, M, Frati, G, \& Schussler, O. Duong Van Huyen JP, Lauret E and Genovese JA. ((2007). Association between a cell-seeded collagen matrix and cellular cardiomyoplasty for myocardial support and regeneration. Tissue Eng , 13, 2681-2687.

[67] Okano, T, Yamada, N, Sakai, H, \& Sakurai, Y. (1993). A novel recovery system for cultured cells using plasma-treated polystyrene dishes grafted with poly (N-isopropylacrylamide). J Biomed Mater Res , 27, 1243-1251.

[68] Furuta, A, Miyoshi, S, Itabashi, Y, Shimizu, T, Kira, S, Hayakawa, K, Nishiyama, N, Tanimoto, K, Hagiwara, Y, Satoh, T, et al. (2006). Pulsatile cardiac tissue grafts using a novel three-dimensional cell sheet manipulation technique functionally integrates with the host heart, in vivo. Circ Res , 98, 705-712.

[69] Ishii, M, Shibata, R, Numaguchi, Y, Kito, T, Suzuki, H, Shimizu, K, Ito, A, Honda, H, \& Murohara, T. (2011). Enhanced angiogenesis by transplantation of mesenchymal stem cell sheet created by a novel magnetic tissue engineering method. Arterioscler Thromb Vasc Biol , 31, 2210-2215.

[70] Sekine, H, Shimizu, T, Hobo, K, Sekiya, S, Yang, J, Yamato, M, Kurosawa, H, Kobayashi, E, \& Okano, T. (2008). Endothelial cell coculture within tissue-engineered cardiomyocyte sheets enhances neovascularization and improves cardiac function of ischemic hearts. Circulation 118,SS152., 145.

[71] Stevens, K. R, Kreutziger, K. L, Dupras, S. K, Korte, F. S, Regnier, M, Muskheli, V, Nourse, M. B, Bendixen, K, Reinecke, H, \& Murry, C. E. (2009). Physiological function and transplantation of scaffold-free and vascularized human cardiac muscle tissue. Proc Natl Acad Sci USA, 106, 16568-16573. 
